Anaesthesist $2021 \cdot 70($ Suppl 1):S1-S10 https://doi.org/10.1007/s00101-020-00760-3 Published online: 24 March 2020

(c) Springer Medizin Verlag $\mathrm{GmbH}$, ein Teil von Springer Nature 2020

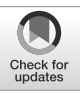

D. Thomas-Rüddel ${ }^{1,2} \cdot$ J. Winning' $\cdot$ P. Dickmann ${ }^{1,2} \cdot$ D. Ouart ${ }^{1,2} \cdot$ A. Kortgen ${ }^{1} \cdot$

U. Janssens ${ }^{3} \cdot$ M. Bauer ${ }^{1,2}$

${ }^{1}$ Dept. of Anesthesiology and Intensive Care Medicine, Jena University Hospital, Jena, Germany

${ }^{2}$ Center for Sepsis Control and Care (CSCC), Jena University Hospital, Jena, Germany

${ }^{3}$ Dept. of Internal Medicine and Internal Intensive Care, St.-Antonius-Hospital Eschweiler, Eschweiler, Germany

\title{
Coronavirus disease 2019 (COVID-19): update for anesthesiologists and intensivists March 2020
}

\section{Introduction}

The novel coronavirus severe acute respiratory syndrome (SARS)-CoV-2 has also reached Germany. Currently, there is no reliable information about its future epidemiological course, the expected number of infected persons or patients who will need hospital treatment and especially the critically ill. Possible scenarios range from a manageable occurrence with a decline in spring to a major pandemia. The outbreak's impact on public health not only depends on the clinical aspects but also on impairments in clinical pathways for other diseases. In the next weeks, every hospital needs to be prepared to face confirmed and suspected infections, bottlenecks in treatment and supplies as well as considerable staff shortages.

For the last few weeks, healthcare systems worldwide have been facing a novel disease. The characteristics, primary infection of the respiratory tract, a relatively high risk of infection and potentially severe progression of the disease, make the SARS-CoV-2 virus and the resulting disease coronavirus disease 2019 (COVID-

This is the English full-text version of the article https://doi.org/10.1007/s00101-020-00758-x
19) a highly relevant topic, not only for intensive care medicine.

In order to provide better care for COVID-19 patients and to plan precautionary measures, this article summarizes the knowledge about the disease as well as specific aspects and recommendations for this medical discipline.

This article deliberately does not focus on epidemiological and virological topics or on preventive measures at the national or societal level. Nonetheless, possible impairments of clinical processes are mentioned even if hospitals might develop individual strategies for coping with them.

Naturally, the level of information is subject to swift changes; new scientific articles are published on a daily basis. Even official recommendations from the Robert Koch Institute (RKI: https://www.rki.de/DE/Content/InfAZ/ N/Neuartiges_Coronavirus/

nCoV_node.html) and from the World Health Organization (WHO: https:// www.who.int/emergencies/diseases/ novel-coronavirus-2019) are being continuously updated and should be referred to in their current version on the internet.

For almost all topics, only observational studies typically with low case numbers and short periods of observation, case reports, expert opinions or experiences with related viral pathogens are available. Current estimates about infectiousness and mortality suggest medium values compared to other relevant viral infections, but variability is high (• Fig. 1). Despite epidemiological and clinical differences, experiences made during the SARS-epidemic in $2002 / 2003$ are partly referred to due to the close relationship of the viruses.

\section{Progression of the disease and severity}

The infection by SARS-CoV-2 is characterized by a large variability of clinical symptoms, from asymptomatic infected persons to mild symptoms up to a small proportion of patients with fatal outcome. There is no pathognomonic clinical picture; however, all publications and reports show similar frequency distributions of symptoms (• Fig. 2).

Almost all patients show fever/ elevated temperature in the course of the disease, although in a large cohort this was true for only $44 \%$ of patients at the time of hospital admission [9]. The second most common symptom is a mostly dry cough. Only every third to fourth patient also produces sputum and hemoptysis is reported only occasionally. "Classical" symptoms of the common cold, such as a sore throat and a blocked or runny nose occur in only around $5-10 \%$ of all recorded cases. Around $5-10 \%$ of patients present with primary gastrointestinal syndromes with diarrhea, nausea and sometimes abdominal 
pain and vomiting. Published cohort studies naturally record mainly patients who are more ill, hospitalized and tested. In studies describing patients with different degrees of severity, most symptoms were more frequent in seriously ill patients so that the individual symptoms are probably less frequent in patients with milder courses of the disease.

\section{Severity of the disease}

In the People's Republic of China around $80 \%$ of all recorded cases show the general symptoms as described above, sometimes combined with mild pneumonia and mild dyspnea. Around every fifth patient develops a severe pneumonia with dyspnea, tachypnea and disturbed gas exchange. Approximately every fourth of these patients, i.e. $5 \%$ of all infected patients, is critically ill with severe lung dysfunction, need for ventilation, shock or extrapulmonary organ failure $[12,13]$. There are no reliable data regarding the additional group of symptom-free or weakly symptomatic cases that have not been tested (- Fig. 3). If this group is sufficiently large-as often assumed-increased testing of mildly symptomatic patients will lead to a shift of the frequencies described above in favor of the milder cases. On the other hand, severely ill patients will be more often recorded in scenarios with limited testing, therefore presenting a larger proportion of severe cases. This phenomenon is probably responsible for the high number of severe courses and fatal outcomes in relation to the total number of confirmed cases in Italy $(10 \%$ critically ill patients), the USA and Iran.

\section{Chronological progression of the disease}

In contrast to many other severe infectious diseases with timespans of only a few days if not hours from onset of symptoms to admission to the intensive care unit (ICU), COVID-19 shows a relatively protracted course with slow deterioration of (primarily) lung function. The median incubation period from exposition to onset of first symptoms is 4 days (interquartile range, IQR 2-7 days), max-

Anaesthesist $2021 \cdot 70$ (Suppl 1):S1-S10 https://doi.org/10.1007/s00101-020-00760-3

(c) Springer Medizin Verlag GmbH, ein Teil von Springer Nature 2020

D. Thomas-Rüddel · J. Winning · P. Dickmann · D. Ouart · A. Kortgen · U. Janssens · M. Bauer „Coronavirus disease 2019“ (COVID-19): update für Anästhesisten und Intensivmediziner März 2020

\section{Zusammenfassung}

Die neu aufgetretene Atemwegserkrankung "Coronavirus disease 2019" (COVID-19) hat Deutschland erreicht. Die Erkrankung verläuft in den meisten Fällen leicht, aber der kleinere Anteil an schwer Erkrankten wird stationär und auch intensivmedizinisch behandelt werden. Im Gegensatz zu anderen akuten Infektionskrankheiten zeigen die schweren Verläufe eine langsame Progredienz von den ersten Symptomen bis zur lebensbedrohlichen Verschlechterung. Die Diagnosestellung erfolgt mithilfe der Polymerase-Kettenreaktion (PCR) aus Proben des Respirationstrakts. Ein schweres „acute respiratory distress syndrome" (ARDS) ist charakteristisch für die kritischen Verläufe. Der Vermeidung nosokomialer Infektionen, insbesondere durch korrekte Anwendung der Schutzausrüstung, und der Aufrechterhaltung des Krankenhausbetriebs kommen zentrale Bedeutung zu. Auch in der Anästhesie und Notfallmedizin ist mit erheblichen Herausforderungen zu rechnen.

Schlüsselwörter

Ausbrüche von Infektionskrankheiten . Infektionskontrolle · Notfallmedizin . Anästhesiologie $\cdot$ Intensivmedizin

\section{Coronavirus disease 2019 (COVID-19): update for anesthesiologists and intensivists March 2020}

\begin{abstract}
The current outbreak of coronavirus disease (COVID-19) has reached Germany. The majority of people infected present with mild disease, but there are severe cases that need intensive care. Unlike other acute infectious diseases progressing to sepsis, the severe courses of COVID19 seemingly show prolonged progression from onset of first symptoms to life-threatening deterioration of (primarily) lung function. Diagnosis relies on PCR using specimens from the respiratory tract. Severe ARDS reflects the hallmark of a critical course of the disease. Preventing
\end{abstract}

nosocomial infections (primarily by correct use of personal protective equipment) and maintenance of hospitals' operational capability are of utmost importance. Departments of Anaesthesia, Intensive Care and emergency medicine will envisage major challenges.

\section{Keywords}

Infectious disease outbreaks · Infection control - Emergency medicine - Anesthesiology . Intensive care imum incubation period is assumed by the RKI to be 14 days; however, there are case reports showing longer incubation periods of up to 19 or 24 days. A median of 10 days from onset of symptoms to admission to the ICU has been reported, from the time of infection it takes nearly 2 weeks (• Fig. 4). This is of considerable relevance for calculating the expected need of ICU beds based on the current epidemiological situation. Faster and slower progression have been reported as well, presumably depending on the specific health care system. Critical courses tend to have a faster progression than milder cases.

\section{Risk factors}

High age, male gender, diabetes, respiratory diseases, cancer, hypertension and arteriosclerotic diseases seem to be important risk factors for severe courses and mortality [5, 6, 8-13]. Age and preexisting illness are known to be highly correlated; however, no regression analyses have been published that describe the independent influence of these different factors. Whether gender differences are due to lifestyle factors or biological differences is not yet clear. Severe courses in children and adolescents are extremely rare, so far no cases of death have been documented for children under 10 years 


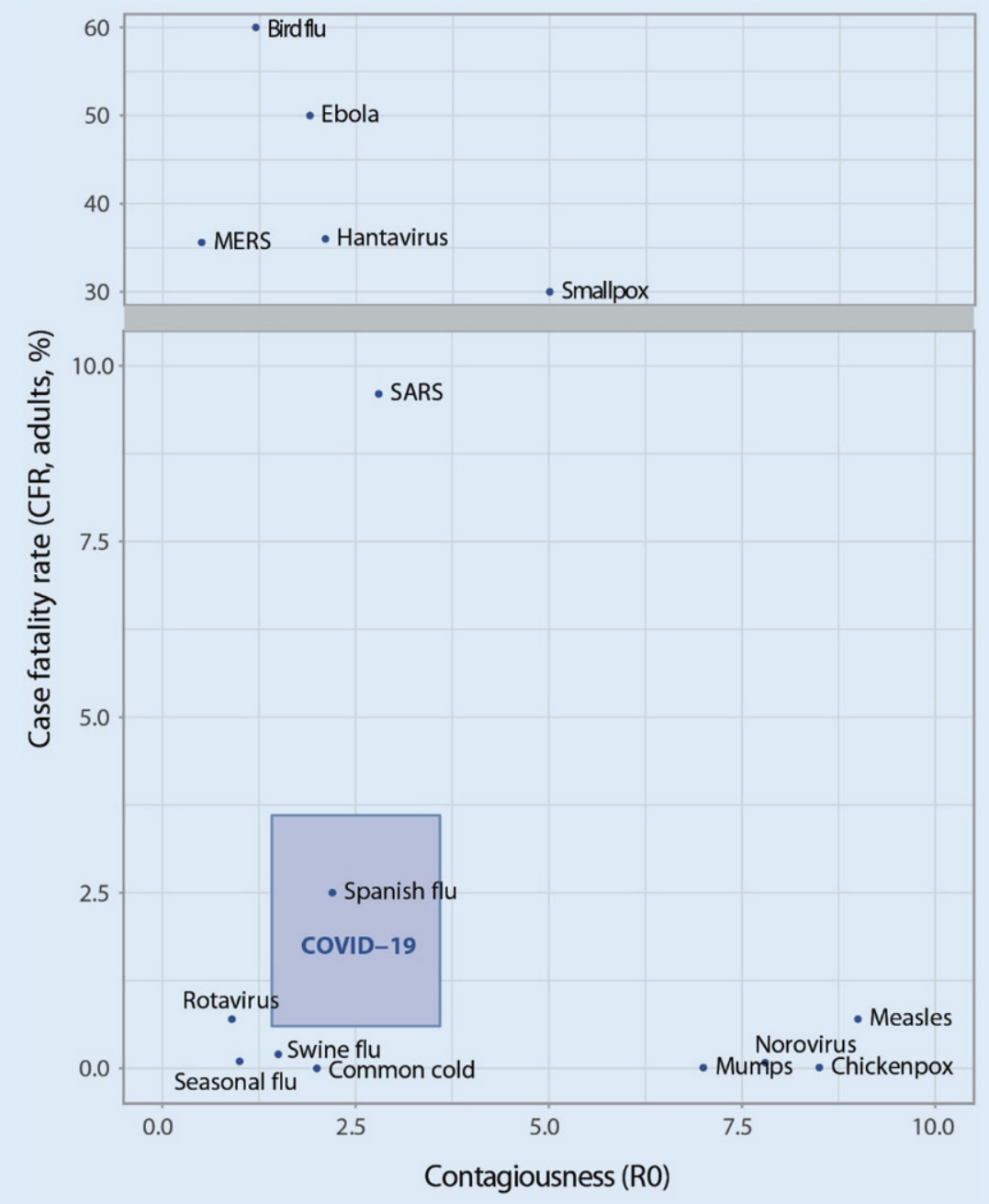

Fig. 1 Mortality rate and contagiousness of selected viral infectious diseases compared to latest COVID-19 estimates. COVID-19 coronavirus disease 2019, MERS Middle East respiratory syndrome, $S A R S$ severe acute respiratory syndrome, $R 0$ basic reproduction number (data from [1-3])

$\begin{array}{lllllllllll}0 & 10 & 20 & 30 & 40 & 50 & 60 & 70 & 80 & 90 & 100[\%]\end{array}$

\begin{tabular}{r|c|c|c|c|c|c|c|}
\hline Elevated temperature & $>95 \%$ & & & & & & $\bullet$ \\
\hline Cough (mainly dry) & $>75 \%$ & & & & & & \\
\hline Fatigue & $40-70 \%$ & & & & & & \\
\hline Mputum production & $20-25 \%$ & & & & & & \\
\hline Myalgia & $10-35 \%$ & & & & & & \\
\hline Headache/confusion & $\sim 10 \%$ & $\bullet$ & & & & \\
\hline Sore throat & $\sim 10 \%$ & $\bullet$ & & & & \\
\hline Nasal symptoms & $\sim 5 \%$ & $\bullet$ & & & & & \\
\hline Diarrhea & $5-10 \%$ & $\bullet$ & & & & & \\
\hline Nausea & $5-10 \%$ & $\bullet$ & & & & & \\
\hline Vomiting & $\sim 5 \%$ & $\bullet$ & & & & & \\
\hline Hemoptysis & Sporadic & & & & & & \\
\hline Chest pain & Sporadic & & & & & & \\
\hline
\end{tabular}

Fig. $2 \Delta$ Frequency of typical symptoms in patients (synopsis from [4-11]) of age [13]. Contrary to the H1N1 influenza epidemic, pregnant and postpartum women do not bear a higher risk [12], while so far no data are available for obesity.

\section{Diagnostics}

Confirmed infection currently depends on pathogen typing using polymerase chain reaction (PCR) diagnostics. Serological tests are being developed but not yet available. In general, testing specimens from the upper and lower respiratory tract is recommended; feces can also sometimes be used for detecting the pathogen. When obtaining specimens from the lower respiratory tract, suitable measures for prevention of nosocomial transmission are obligatory for the personnel, including wearing filtering face piece (FFP3) masks. The current flow diagram (- Infobox 1 ) of the RKI recommends this only for severely ill patients who need inpatient care. In outpatient settings, only obtaining specimens from the upper respiratory tract is recommended.

False negative results are described where poor specimen quality, inadequate transportation and also not yet existing viral shedding are discussed as possible causes; however, there are well documented cases where in spite of initially obvious symptoms and chest computed tomography (CT) findings, several smear tests from the upper respiratory tract were negative, while after 8 days, the results were positive [14]. This suggests that there are cases with an initially isolated infection of the lower respiratory tract. For this reason, it is thought that in critically ill patients with suspected COVID19 , specimens should always be obtained from the lower respiratory tract, in particular if prior testing from the upper respiratory tract was negative.

Whether patients or persons who were potentially exposed should be tested needs to be decided individually, taking the current epidemiological development into account. Updated recommendations of the RKI, in particular regarding the suspected COVID19 symptoms that require testing, can be found on the internet. As situation- 

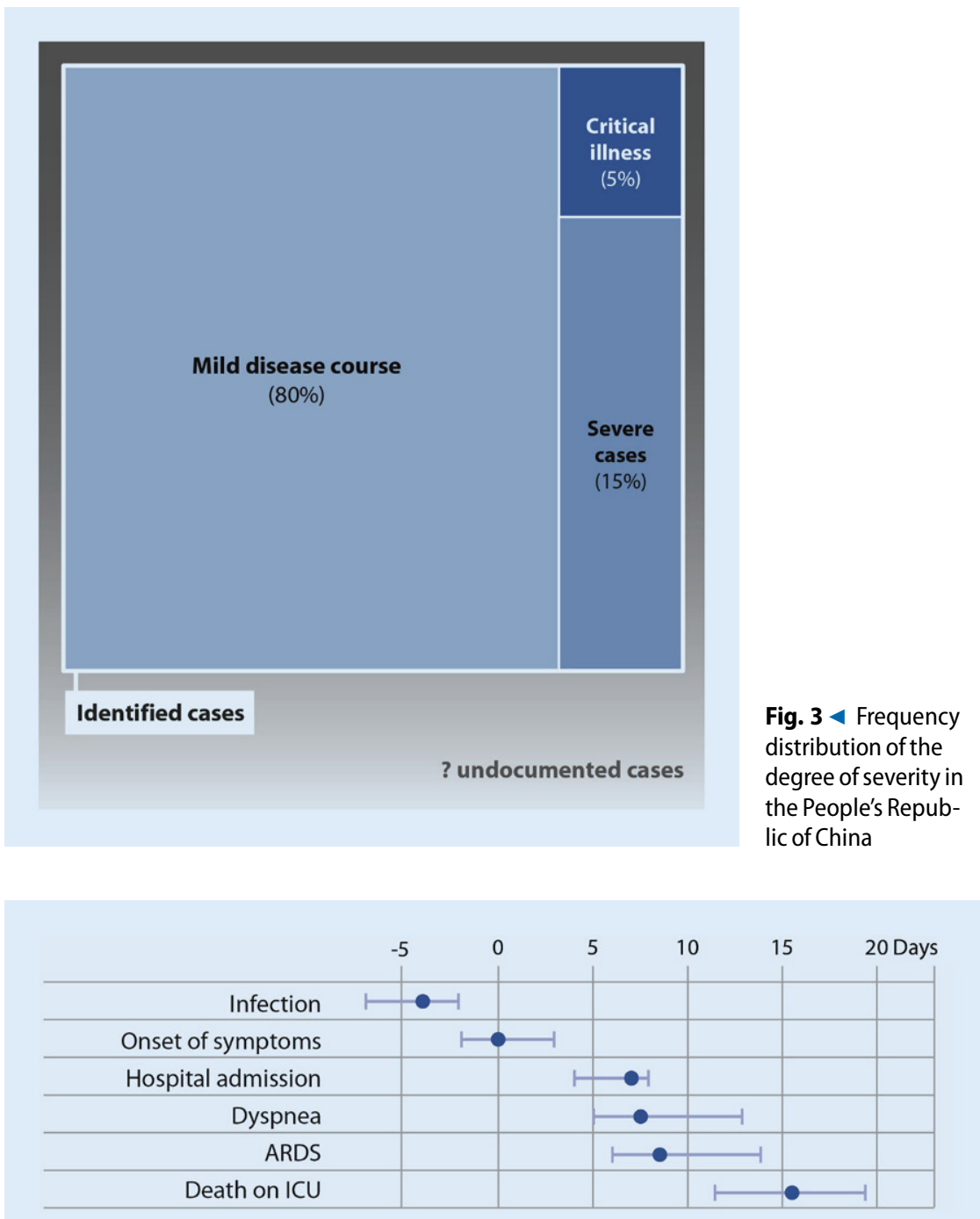

Fig. $4 \Delta$ Median chronological course of symptoms and interquartile range (IQR) estimated according to $[5-9,11]$. Hospital admission and dyspnea, acute respiratory distress syndrome (ARDS) and death on Intensive Care Unit (ICU) only in case of increasing severity

related adaptations of recommendations were previously made each week and as further updates are expected, this article refrains from a detailed repetition and recommends a case-related consultation of the currently valid version of the flow chart (see OInfobox 1). The authors recommend including SARSCoV-2 infection into the differential diagnostic considerations when admitting patients with respiratory insufficiency to the ICU, and not to apply testing criteria too restrictively. The overall goal has to be to detect as many as possible of the cases that have not been identified until they were admitted to the ICU, as has been reported from earlier phases of the pandemic e.g. in Spain, Italy and the USA.

\section{Laboratory findings and imaging investigations}

Typical findings of imaging and clinical laboratory results are shown in $\bullet$ Fig. 5. The CT diagnostics seem to be sensitive; however, due to the unspecific findings, neither imaging nor laboratory diagnostics seem to be suitable for diagnosis or exclusion diagnostics.

\section{Infobox 1}

Flowchart suspicion clarification and

measures by the RKI

https://doi.org/10.25646/6473

RKI-information on COVID-19

https://www.rki.de/DE/Content/InfAZ/N/

Neuartiges_Coronavirus/nCoV.html

\section{Transmission risks and hygiene measures}

\section{Transmission route and hygiene measures}

Present knowledge suggests transmission via respiratory droplets and direct contact with body fluids and excretions. In addition to general rules for basic hygiene and hand hygiene, the RKI recommends accommodation of in-patients in single rooms, ideally with a vestibule or double door system. Air-conditioning systems need to be turned off or adapted so that no dissemination to other rooms or corridors is possible as this would be the case with air circulation systems or overpressure ventilation. Preparatory planning with hospital hygiene and facility management is recommended immediately in preparation for more patients to be admitted. Daily wiping disinfection of areas that are close to patients is also recommended: updated recommendations can be found on the RKI webpage.

\section{Nosocomial transmissions, infections of medical personnel}

It has been reported that in the SARS epidemic $20 \%$ of all infected persons were medical personnel (in Canada and Singapore even $40 \%$ ), and that nosocomial infections played a major role in the epidemiological course of events [16]. For SARS-CoV-2 that situation is different; most infections take place outside hospital. Among other reasons, this is due to the fact that contagiousness and infectiousness of mildly symptomatic patients and probably also of asymptomatic infected persons are higher [17]; however, for epidemiological reasons and also because the risk they present for staff, including related fears and impairment to healthcare system functionality, 


\begin{tabular}{|c|c|c|c|}
\hline Findings & Frequency & Comment & \\
\hline Imaging - lungs & & $\begin{array}{l}\text { In thoracic X-ray no detectable changes in } \\
40 \% \text { of patients. CT-diagnostics with frosted } \\
\text { glass-like changes, but also infiltrates on one } \\
\text { or both sides. }\end{array}$ & \\
\hline $\begin{array}{l}\text { Hypersensitive } \\
\text { troponin }\end{array}$ & $\begin{array}{l}\text { Increase in up to } \\
12 \% \text { of cases }\end{array}$ & $\begin{array}{l}\text { More frequent in ICU patients. Severity of } \\
\text { myocardial injury associated with outcome. }\end{array}$ & \\
\hline $\begin{array}{l}\text { ASAT/ALAT (aspartate } \\
\text { or alanine amino- } \\
\text { transferase) }\end{array}$ & $\begin{array}{l}\text { Increase in } 22- \\
38 \% \text { of cases }\end{array}$ & $\begin{array}{l}\text { More frequent in ICU patients. } \\
\text { Significance unclear. }\end{array}$ & \\
\hline Lymphocytopenia & $\begin{array}{l}\text { In } 32-83 \% \text { of } \\
\text { cases }\end{array}$ & $\begin{array}{l}\text { Occurs frequently with Covid-19 } \\
\text { infections. Severity of lymphocytopenia } \\
\text { and lacking recovery seem to be } \\
\text { associated with severity of the disease } \\
\text { and outcome. }\end{array}$ & \\
\hline $\begin{array}{l}\text { Lactate } \\
\text { dehydrogenase (LDH) }\end{array}$ & $\begin{array}{l}\text { Increase in } 21- \\
76 \% \text { of cases }\end{array}$ & $\begin{array}{l}\text { Level seems to be associated } \\
\text { with severity of disease and } \\
\text { outcome. }\end{array}$ & \\
\hline Procalcitonin (PCT) & $\begin{array}{l}\text { Relevant } \\
\text { increase in less } \\
\text { than } 10 \% \text { of } \\
\text { cases }\end{array}$ & $\begin{array}{l}\text { PCT-increase apparently not } \\
\text { obligatory in COVID. Might } \\
\text { hint at co-infection. }\end{array}$ & \\
\hline
\end{tabular}

Fig. $5<$ Typical changes in laboratory values and imaging findings (synopsis from $[4-12,15])$

nosocomial infections are still important and need to be minimized by suitable measures. According to official figures, in China $3.8 \%$ of all cases were medical staff, corresponding to approximately 2000 cases. In the Italian region of Lombardy, it was officially stated at the beginning of March that $10 \%$ of all physicians and nurses were tested positive for SARSCoV-2 and were not available for patient care. A case series with 138 patients in a university hospital in Wuhan has shown an infection rate of $29 \%$ of the medical staff, and the incidence of nosocomial infections among patients was $12 \%[6,11]$. The majority of infections took place on the general wards; only 2 cases were reported for ICU. A quarter of nosocomial cases in medical staff and fellow patients were traced back to a single patient who was admitted to the general surgery department because of primarily abdominal symptoms.

\section{Personal protective equipment}

The WHO and the RKI recommend slightly different measures for personal protection equipment (•Table 1$)$. Regarding specific features of aerosol generating procedures, further information is given in the next section. Using eye protection (safety goggles or visor) in addition to normal safety equipment has been proven to provide a significant reduction of nosocomial transmission in the SARS epidemic [18] and is thus suggested in the care of COVID-19 patients. Wearing medical headgear does not offer additional protection, but it might help reduce unintentional hand-face contact and makes putting on the protective equipment without contamination easier. Make sure that FFP2/3 masks sit tightly; bearded men may require shaving. Figure 6 shows a complete protection equipment as an example. Putting on the protection gear in a correct way, and in particular taking it off without contamination, requires training. Ideally, pictured instructions are available in each double door system changing area. If available, a powered air-purifying respirator (PAPR) can of course be used, especially for activities or in areas with particularly high risks.

\section{High-risk measures}

Due to transmission by droplet infection, transmission risks naturally increase with all measures that generate aerosols. - Table 2 provides an overview of risky measures and possible minimization strategies. In the context of the SARS epidemic, the following measures were identified as most important risk situations: intubation, noninvasive ventilation, mask ventilation and manipulation of oxygen masks $[18,19]$ as well as resuscitation [20]. The risk for assistant personnel was at least as high as for the intubating person [19]. It must, however, be stated that at least in Canada intubation standards with nebulization of topical anesthetics and without muscle relaxants were apparently used [21]. Interestingly enough, applying ECG electrodes was also associated with a high risk [18].

\section{Emergency medicine aspects}

Due to the abovementioned course of disease that is initially relatively protracted, the large number of mild cases and the very high alertness for SARS-CoV-2 infection in the general public, outpatient diagnostics, treatment and care play a major role. Telephone hotlines and special diagnostic centers for patients with fever should be organized in close collaboration with hospitals, public health offices 
Table 1 Personal protection gear in treatment of SARS-CoV-2 patients

\begin{tabular}{|l|ll}
\hline & WHO recommendation & RKI recommendation \\
\hline Normal patient care & $\begin{array}{l}\text { Mouth-nose protection } \\
\text { (MNP) } \\
\text { Eye protection } \\
\text { Medical coat } \\
\text { Gloves }\end{array}$ & $\begin{array}{l}\text { FFP2 mask } \\
\text { Medical coat } \\
\text { Gloves }\end{array}$ \\
$\begin{array}{ll}\text { Measures with aerosol genera- } \\
\text { tion, e.g. intubation or noninva- } \\
\text { sive ventilation }\end{array}$ & $\begin{array}{l}\text { In addition: } \\
\text { FFP2 instead of MNP } \\
\text { Apron or waterproof coat }\end{array}$ & $\begin{array}{l}\text { In addition: } \\
\text { FFP2 instead of MNP } \\
\text { Apron or waterproof coat } \\
\text { Eye protection }\end{array}$ \\
\hline FFP filtering face piece, RKI Robert & Koch Institute, WHO World Health Organization \\
\hline
\end{tabular}

Table 2 Aerosol generating measures and risk minimization

\begin{tabular}{|c|c|}
\hline $\begin{array}{l}\text { Aerosol generating } \\
\text { measures }\end{array}$ & Possible ways of risk minimization \\
\hline \multirow[t]{6}{*}{ Intubation $[18,22,23]$} & Only experienced staff \\
\hline & Early and well prepared \\
\hline & Avoid emergency intubation \\
\hline & Avoid intermediate ventilation, RSI \\
\hline & Sufficient depth of anesthesia and relaxation \\
\hline & Immediate wrapping of used spatula \\
\hline \multirow[t]{2}{*}{ Bronchoscopy } & Avoid awake bronchoscopy \\
\hline & Consider relaxation \\
\hline \multirow[t]{3}{*}{ Resuscitation [20] } & Do not neglect personal protection gear in emergencies \\
\hline & Swift airway management, minimize mask ventilation \\
\hline & Keep the team involved small \\
\hline Suction & Closed suction systems \\
\hline \multirow[t]{3}{*}{ NIV/HFNO [18] } & Highly restrictive indications \\
\hline & Specific staff instruction \\
\hline & Mouth-nose protection for patients with HFNO \\
\hline \multirow[t]{5}{*}{ Tracheotomy } & Only experienced staff \\
\hline & Keep the team on the patient small \\
\hline & Sufficient relaxation \\
\hline & $\begin{array}{l}\text { Ventilator in standby between tracheal puncture and placement of } \\
\text { the tracheal cannula }\end{array}$ \\
\hline & If justifiable, wait for negative PCR \\
\hline \multirow{2}{*}{$\begin{array}{l}\text { Disconnection of } \\
\text { ventilation }\end{array}$} & Clamp tube \\
\hline & HME filter \\
\hline \multirow[t]{2}{*}{ Extubation } & Reconsider standard procedure (suction, recruitment maneuvre) \\
\hline & Disconnect ventilator early enough \\
\hline
\end{tabular}

and the Association of Statutory Health Insurance Physicians. In addition, implementing permanent home visit teams to do smear tests might be useful. An indication for hospital admission only exists in cases of a severe clinical manifestation of COVID-19 or because of other diseases, injuries or unclear symptoms. The mere proof of SARS-CoV-2 or mild symptoms does not qualify for hospital admission. Emergency medical services, rescue service headquarters, public health offices, health insurance physicians and hospitals should closely coordinate regional approaches, solutions, structures and burden sharing.

Treatment of SARS-CoV-2 infections by emergency doctors or emergency medical services should only be necessary in exceptional cases. Emergency doctors should minimize contact with patients or suspected cases. To this end, headquarters need to be sensitized and regularly trained according to up to date RKI information. Ideally, this information is updated automatically on headquarter computers. In situations that are not life-threatening, patients should be referred to outpatient healthcare structures. In cases of real emergency operations, rescue services need to be informed about the suspicion. Rescue services need to have suitable personal protection equipment ready for use. The emergency services staff/emergency doctor is responsible for evaluating if a patient's clinical symptoms require hospital admission or if further outpatient treatment needs to be arranged. If hospital admission is necessary, the patient is driven to the nearest suitable hospital. Flooding large medical centers with oligosymptomatic patients needs to be avoided by all means. If possible, the patient should wear mouth-nose protection (MNP) during transportation. Additionally, windows or doors between treatment room and driver's cabin of the ambulance must be closed and ventilation systems in the treatment room shut off. Consider presence of staff in the treatment room carefully, depending on the patient's condition.

Due to its temporal dynamics, it is possible that over the course of an epidemic an increased number of patients with deterioration of symptoms subsequently needs to be admitted to hospital. Regarding logistics and consumption of materials, deployment of specially dispatched rescue services may be useful in this case.

\section{Considerations for anesthesia}

For patients with confirmed SARSCoV-2 infection and for suspected cases, there will be indications for surgery because of complications in the course of treatment or due to other reasons that might be unrelated to the infection. Ideally, it should be clarified in advance which operating rooms are suitable for the procedure and how to modify the 


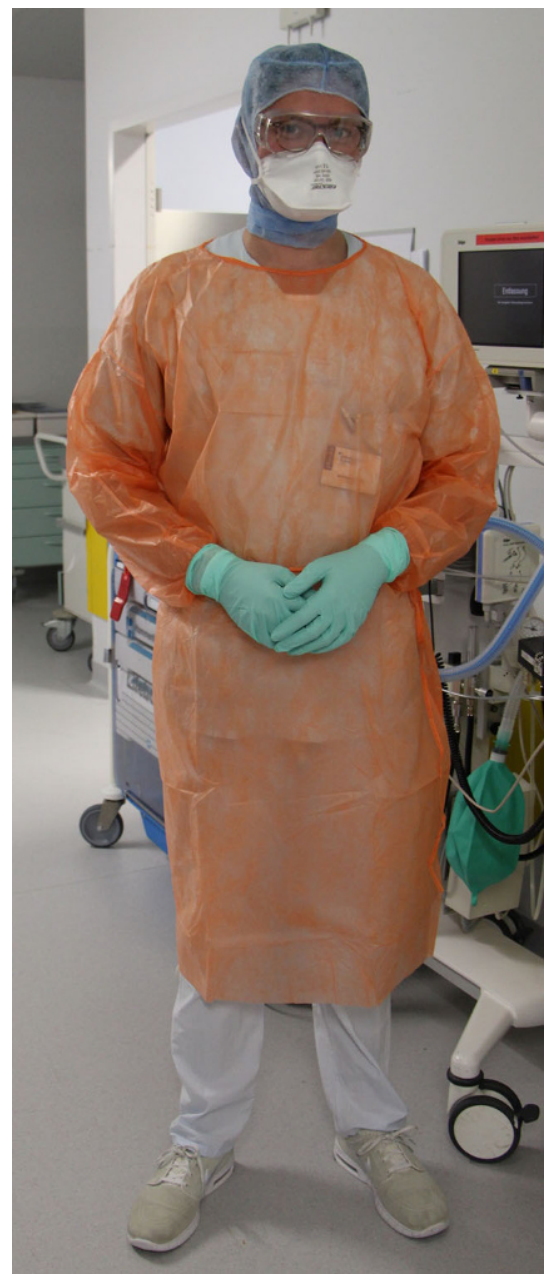

Fig. $6 \Delta$ Colleague in complete personal protection gear

ventilation system settings. Patients who are not yet intubated should wear mouth-nose protection until induction and also immediately after end of anesthesia. Because of the risk situations at applying the monitoring, intubation and extubation as described, only experienced staff in small teams wearing full personal protection should be deployed [23]. Entering the operating suite via holding areas and leaving via recovery rooms must be avoided. By analogy to flu, bag valve masks and tubes should be changed when using a respiratory gas filter [24]. This instruction is based on a joint recommendation of the German Society of Hospital Hygiene (DGKH) and the German Society of Anesthesiology and Intensive Care (DGAI) in 2010; however, this does not concern the anesthesia circuit system or filterbased gas analysis far from the patient.

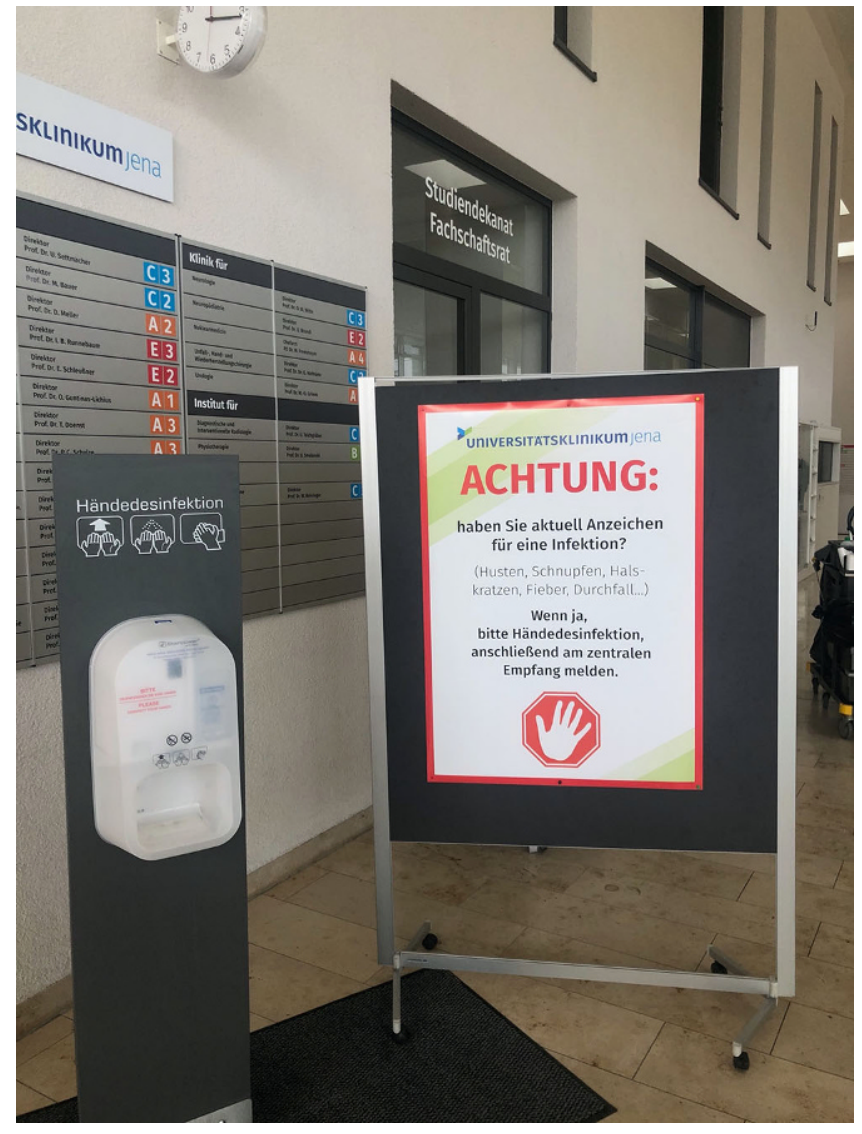

Fig. $7<$ Information sign for visitors and patients, distribution of mouth-nose protection to symptomatic persons
Premedication clinics and recovery rooms are functional areas where a high number of staff and patients meet in close proximity. Depending on the dynamics of the infection, it may be necessary to change procedures here or even close whole areas in order to avoid nosocomial chains of infection that are difficult to track. It seems reasonable to put up signs for visitors, asking them to immediately get in touch with medical staff in case of symptoms of infection. They will then get mouth-nose protection and will be asked to stay away from other visitors, patients and staff in order to reduce infection risks (e.g. - Fig. 7). For outpatient pain clinics, the situation is in principle similar.

It seems also reasonable to discuss all procedures with all people involved at an early stage for joint development of solutions that work in the respective setting.

\section{Intensive care}

\section{Respiratory failure and ARDS}

An absolute majority of all critically ill COVID-19 patients present with severe respiratory insufficiency $[8,10-12,15]$. Sometimes clinical signs of dyspnea may be missing even in cases of severe hypoxia, especially in older patients [15]. At least in the specific situation in Hubei, in China most severe oxygenation failures with an oxygenation index $<100 \mathrm{~mm} \mathrm{Hg}$ $[8,12]$ were already present when patients were admitted to ICU. Treatment with noninvasive ventilation or high-flow oxygen, as has become established for primary hypoxemic lung failure in the last few years, is critically discussed for COVID-19 treatment and many experts reject this approach $[12,22,25]$. Success rates in critically ill COVID-19-patients are limited, delayed intubation is associated with poor outcome and the treatment as well as a possibly necessary emergency intubation in cases of treatment failure increase the risk for 
transmission to staff $[8,12,15,22]$; however, in situations with an imbalanced resources-needs ratio, this approach could help bridge the time until decision-making and intubation, or it could also be a therapeutic option in cases of lacking ventilatory capacities. For ARDS therapy, the commonly known intensive care principles apply, as e.g. documented in the S3 guidelines invasive ventilation. Classical rescue therapies for severe oxygenation failure, such as recruitment, relaxation and prone positioning are primarily successful in most patients [12, 15]. In the course of time some of the patients develop severe hypercapnia of unknown origin [12]. Barotrauma, often observed in SARS, has been reported only in single cases; however, this might result from a trend towards more lungprotective ventilator settings compared to 2003 [8].

Whether or not patients benefit from extracorporeal membrane oxygenation (ECMO) therapy is not clear $[15,26]$. If one basically assumes prognosis improvement with ECMO therapy in ARDS patients, then this should also apply for COVID-19 given the prominent pulmonary organ failure and the relative rarity of extrapulmonary organ failure. In a series of 28 cases, 14 had died, 5 were weaned and 9 were still under ECMO therapy at the time of manuscript submission [15]. In the case of larger numbers of patients, a lack of ECMO treatment facilities is to be expected. Good patient selection and timely start are likely crucial for successful implementation.

In ICD-10-GM, COVID-19 was given the coding U07.1! as pathogen-specific secondary diagnosis code. Attention should be paid to correct coding.

\section{Pharmacological therapy}

Many antiviral and other agents are being used in patients, their application based on theoretical considerations, case studies and in vitro data about SARS and Middle East respiratory syndrome (MERS). Several clinical trials are being conducted. Most commonly used seem to be remdesivir, lopinavir/ ritonavir $\left(\right.$ Kaletra $\left.^{\circledR}\right)$, also in combination with interferon beta $1 \mathrm{~b}$ and chloroquine [27-30]; however, the current data situation does not allow concrete treatment recommendations for any of these substances. The substances' pharmacokinetic interaction potential is not without problems (http://www.covid19druginteractions.org/). The WHO as well as Chinese experts clearly advise against use of steroids because prolonged virus replication without clinical benefits was observed under steroid therapy in MERS [12, 25]. Delayed dramatic deterioration after initial improvement under protracted steroid application has been reported anecdotally for COVID19 [12]; however, there is no consensus regarding benefit or harm of short-term steroid administration, and it is still being used [11].

Bacterial superinfections are reported, but they seem to occur less frequently than in influenza pneumonia. Empirical antibiotic therapy for community or nosocomially acquired pneumonia is recommended for all severely ill patients [25]. As known for influenza, Aspergillus co-infections can occur as well [4].

\section{Extrapulmonary organ failure}

Shock is relatively rarely observed; in total, no more than up to one third of critically ill patients need catecholamine treatment $[5,8,9,11,12,15,31,32]$; however, some patients die of refractory heart failure after some time in the course of disease, showing aspects of cardiogenic shock [10, 12]. It is not clear whether this results from a direct myocardial damage by infection, stress cardiomyopathy or right heart failure due to prolonged ARDS. Histological or echocardiographical findings have not been reported yet. Many patients suffer from kidney damage, around 20\% need renal replacement therapy in the course of disease [8, 10-12]. As in all ICU patients, in cases of newly occurring shock with multiorgan failure there is strong suspicion of nosocomial infection with sepsis $[8,12]$.

\section{Strategic considerations for referrals}

Referring suspected cases or patients, especially if they are severely ill, to maximum care hospitals may seem to be an attractive strategy and is well-established practice in Germany for patients with severe, complex or rare medical conditions; however, such an approach would overburden maximum health care providers and would bring their functionality, e.g. as transregional trauma center, perinatal center, transplantation center and other highly specialized areas of care, to a halt. For this reason, community hospitals should provide intensive care for patients with COVID19. Referral seems to only be sensible for few, well-selected patients with medical indications, e.g. for ECMO therapy.

\section{Prognosis and sequelae of the disease}

For COVID-19 patients treated on ICU, a mortality rate of $30-70 \%$ is expected $[5,8,10,11,13,15]$. For older patients with ARDS, this is an entirely expectable estimation that is comparable to other severe pulmonary infections. In Hubei, the Chinese province that was initially most affected and where most of the data come from, access to intensive care treatment was delayed and the quality of care was probably reduced due to the exceptional situation. Thus, in one case series transfer to ICU took place a median of 1.5 days after onset of ARDS [5], in another case series some of the patients were treated on newly established ICUs [8], other authors report that only $25 \%$ of deceased patients were intubated and invasively ventilated at all [15]. In survivors, usual consequences of long-term intensive care treatment have to be expected. For survivors of the SARS epidemic, a high rate of pulmonary fibrosis is reported [33]. As there is also one case report with a newly emerged fibrosis in a COVID-19 patient [34], COVID-19 survivors should be followed-up closely. 


\section{Infobox Additional information in English}

https://www.esicm.org/resources/ coronavirus-public-health-emergency/ https://www.who.int/emergencies/diseases/ novel-coronavirus-2019

https://www.ecdc.europa.eu/en/novelcoronavirus-china

\section{Impairment of clinical processes}

Depending on the future progress of infection, and also on measures taken, significant impairments of clinical processes are to be expected that do not directly result from the inflow of COVID patients. Due to the following factors, considerable staff shortages that are difficult to plan are very likely:

- Staff fall ill

- Staff need to care for ill relatives

- Staff need to care for their children when schools and kindergartens are closed

- Staff need to care for relatives if ambulatory services stop working

- Staff are in fear for their own health

- Mental overload

To meet these challenges, alternative structures of care, especially for children, need to be established, and measures for consequent avoidance of nosocomial infections and transmission of diseases, e.g. in cafeterias and meetings, as well as optimized communication and information should be implemented. Recruiting additional staff, e.g. from the group of medical trainees and students, office staff and retired former colleagues should be considered at an early stage. Depending on the situation, and in close cooperation with local health authorities, quarantining clinically asymptomatic medical staff after SARS-CoV-2 contact needs to be carefully traded off against resulting staff shortage in patient care. Regular information about current preparations and adaption measures, the number of infected patients who actually need care as well as measures for protecting staff (protection gear, skill training and other activities) can help to ensure patient care in situations with high workloads and stress.

Apart from this, an inventory of available resources of rooms and consumables should be done at an early stage, and strategies should be developed to plan how to deal with possible shortages of isolation rooms, personal protection gear and also supply bottlenecks of crucial drugs. To this end, it is important to consider the hospital and healthcare center regional characteristics, and to develop joint approaches with all professional groups involved about timely detection and compensation for impairments and shortages in times of work intensification.

The checklist published by the European Center for Disease Prevention and Control (ECDC) is helpful for preparation (https://www.ecdc.europa.eu/en/ publications-data/checklist-hospitalspreparing-reception-andcare-coronavirus-2019-covid-19).

Due to supply bottlenecks, staff needs to be economical with personal protective gear, especially with FFP2/3 masks. Wearing these masks in situations that do not require their use needs to be prevented by better explanation. Feardriven stockpiling by departments that are not involved in the care of infectious patients and taking stock out of hospital needs to be prevented by measures in materials logistics and by storing these materials on the wards. The importance of early-stage preparation in the abovementioned areas was underlined by an appeal made by intensive care physicians from heavily affected northern Italy to their European colleagues (https://www. esicm.org/covid-19-update-from-ourcolleagues-in-northern-italy/).

\section{Summary for clinical practice}

- The COVID-19 epidemic confronts the disciplines with major challenges.

- In most cases, the course of the disease is mild, but around 5\% of patients develop severe ARDS.

- It is necessary to establish structures for providing outpatient care for as many mild cases as possible.

- Pathogen identification is done by PCR, in critically ill patients preferably from the lower respiratory tract.

- NIV therapy or even high-flow oxygen must be assessed critically due to high risk of infection for staff.

- If NIV is nonetheless applied, early intubation is needed in case of failure.

- Unlike other severe infectious diseases, COVID-19 patients often deteriorate only with a certain delay in the course of disease.

- Avoiding nosocomial COVID infection is crucial, above all by consequent use of personal protective gear.

- Apart from challenges regarding patient care, staff absences and lack of resources can cause considerable problems in hospitals' operational processes.

- Structures that provide the care of other medical conditions, e.g. trauma, myocardial infarction or births, need to be maintained at all costs.

\section{Corresponding address}

Prof. Dr. M. Bauer

Dept. of Anesthesiology and Intensive Care Medicine, Jena University Hospital Am Klinikum 1, 07747 Jena, Germany

Michael.bauer@med.uni-jena.de

Acknowledgements. The authors thank Dr. M. Leitner for creating the graphics, Dr. I. Salzmann for the protection gear photograph and C. Weinmann for support with translating this article.

\section{Compliance with ethical guidelines}

Conflict of interest. D. Thomas-Rüddel, J. Winning, P. Dickmann, D. Ouart, A. Kortgen, U. Janssens and $M$. Bauer declare that they have no competing interests.

For this article no studies with human participants or animals were performed by any of the authors. All studies performed were in accordance with the ethical standards indicated in each case.

\section{References}

1. Gardner L (2020) Update January 31 : Modeling the Spreading Risk of 2019-nCoV. In: Johns Hopkins Center for Systems Science and Engineering (https://systems.jhu.edu/research/public-health/ ncov-model-2/) 
2. Imai N, Cori A, Dorigatti I, Baguelin M, Donnelly CA, Riley S, Ferguson N (2020) Report 3: Transmissibility of 2019-nCoV. In: Imperial College London (https://www.imperial.ac.uk/ media/imperial-college/medicine/sph/ide/gidafellowships/Imperial-2019-nCoV-transmissibility. pdf.)

3. McCandless D, Kashan O, Quick M, Webster K, Starling S (2020) The microbe scope-infectious diseases in context. In: Information is beatiful (https:// informationisbeautiful.net/visualizations/themicrobescope-infectious-diseases-in-context/.)

4. Chen N, Zhou M, Dong X, Qu J, Gong F, Han Y, Qiu Y, Wang J, Liu Y, Wei Y et al (2020) Epidemiological and clinical characteristics of 99 cases of 2019 novel coronavirus pneumonia in Wuhan, China: a descriptive study. Lancet 395(10223):507-513

5. Huang C, Wang Y, Li X, Ren L, Zhao J, Hu Y, Zhang L, Fan G, Xu J, Gu X et al (2020) Clinical features of patients infected with 2019 novel coronavirus in Wuhan, China. Lancet 395(10223):497-506

6. Wang D, Hu B, Hu C, Zhu F, Liu X, Zhang J, Wang B, Xiang $\mathrm{H}$, Cheng $\mathrm{Z}$, Xiong $\mathrm{Y}$ et al (2020) Clinical Characteristics of 138 Hospitalized Patients With 2019 Novel Coronavirus-Infected Pneumonia in Wuhan, China. JAMA. https://doi.org/10.1001/ jama.2020.1585

7. Wu J, Liu J, Zhao X, Liu C, Wang W, Wang D, Xu W, Zhang C, Yu J, Jiang B et al (2020) Clinical characteristics of imported cases of COVID-19 in Jiangsu province: a multicenter descriptive study. Clin Infect Dis. https://doi.org/10.1093/cid/ ciaa199

8. Yang $X, Y u$ Y, Xu J, Shu H, Xia J, Liu H, Wu Y, Zhang L, Yu Z, Fang M et al (2020) Clinical course and outcomes of critically ill patients with SARSCoV-2 pneumonia in Wuhan, China: a singlecentered, retrospective, observational study. Lancet Respir Med. https://doi.org/10.1016/ S2213-2600(20)30079-5

9. Guan W-J, Ni Z-Y, Hu Y, Liang W-H, Ou C-Q, He J-X, Liu L, Shan H, Lei C, Hui DSC et al (2020) Clinical characteristics of Coronavirus disease 2019 in China. N Engl J Med. https://doi.org/10.1056/ NEJMoa2002032

10. Ruan Q, Yang K, Wang W, Jiang L, Song J (2020) Clinical predictors of mortality due to COVID-19 based on an analysis of data of 150 patients from Wuhan, China. Intensive Care Med. https://doi. org/10.1007/s00134-020-05991-x

11. Cao J, Hu X, Cheng W, Yu L, Tu WJ, Liu Q (2020) Clinical features and short-term outcomes of 18 patients with corona virus disease 2019 in intensive care unit. Intensive Care Med. https://doi.org/10. 1007/s00134-020-05987-7

12. Medicine ESOIC (2020) ESICM Webinar-update on Coronavirus. In: ESICM Webinar. European society of intensive care medicine

13. Wu Z, McGoogan JM (2020) Characteristics of and Important Lessons From the Coronavirus Disease 2019 (COVID-19) Outbreak in China: Summary of a Report of 72314 Cases From the Chinese Center for Disease Control and Prevention. JAMA. https:// doi.org/10.1001/jama.2020.2648

14. Xie X, Zhong Z, Zhao W, Zheng C, Wang F, Liu J (2020) Chest CT for typical 2019-ncoV pneumonia: relationship to negative RT-PCR testing. Radiology https://doi.org/10.1148/radiol.2020200343

15. Xie J, Tong Z, Guan X, Du B, Qiu H, Slutsky AS (2020) Critical care crisis and some recommendations during the COVID-19 epidemic in China. Intensive Care Med. https://doi.org/10.1007/s00134-02005979-7
16. Ho PL, Tang XP, Seto WH (2003) SARS: hospital infection control and admission strategies. Respirology 8(Suppl):S41-S45

17. Bai Y, Yao L, Wei T, Tian F, Jin DY, Chen L, Wang M (2020) Presumed asymptomatic carrier transmission of COVID-19. JAMA. https://doi.org/ 10.1001/jama.2020.2565

18. Raboud J, Shigayeva A, McGeer A, Bontovics E, Chapman M, Gravel D, Henry B, Lapinsky S, Loeb M McDonald LC et al (2010) Risk factors for SARS transmission from patients requiring intubation: a multicentre investigation in Toronto, Canada. Plos One 5(5):e10717

19. Fowler RA, Guest CB, Lapinsky SE, Sibbald WJ, Louie M, Tang P, Simor AE, Stewart TE (2004) Transmission of severe acute respiratory syndrome during intubation and mechanical ventilation. Am JRespir Crit Care Med 169(11):1198-1202

20. Christian MD, Loutfy M, McDonald LC, Martinez KF, Ofner $M$, Wong $T$, Wallington $T$, Gold WL, Mederski B, Green K et al (2004) Possible SARS coronavirus transmission during cardiopulmonary resuscitation. Emerg Infect Dis 10(2):287-293

21. Cooper A, Joglekar A, Adhikari N (2003) A practical approach to airway management in patients with SARS. Cmaj 169(8):785-787

22. Cheung JC, Ho LT, Cheng JV, Cham EYK, Lam KN (2020) Staff safety during emergency airway management for COVID-19 in Hong Kong. Lancet Respir Med. https://doi.org/10.1016/S22132600(20)30084-9

23. Foundation APS (2020) Perioperative considerations for the 2019 novel Coronavirus (COVID-19). In: Anesthesia patient safety foundation

24. Kranabetter R, Kramer A, Rathgeber J, Zuchner K, Assadian O, Daeschlein G, Hubner NO, Dietlein E, Exner M, Grundling M et al (2010) Prevention of infections under anesthetic breathing with breathing filters: concerted recommendations of the Deutsche Gesellschaft fur Krankenhaushygiene e. V. (DGKH) and the Deutsche Gesellschaft fur Anasthesiologie und Intensivmedizin e. V. (DGAI). Anaesthesist 59(12):1124-1132

25. WHO (2020) Clinical management of severe acute respiratory infection when novel coronavirus (nCoV) infection is suspected. In.: World Health Organization, Genf. WHO Reference Number: WHO/2019-nCoV/clinical/2020. https:// www.who.int/publications-detail/clinicalmanagement-of-severe-acute-respiratoryinfection-when-novel-coronavirus-(ncov)infection-is-suspected

26. MacLaren G, Fisher D, Brodie D (2020) Preparing for the most critically ill patients with COVID-19: the potential role of extracorporeal membrane oxygenation. JAMA. https://doi.org/10.1001/ jama.2020.2342

27. Wong JEL, Leo YS, Tan CC (2020) COVID-19 in Singapore-current experience: critical global issues that require attention and action. JAMA. https://doi.org/10.1001/jama.2020.2467

28. Del Rio C, Malani PN (2020) COVID-19-new insights on a rapidly changing epidemic. JAMA. https://doi. org/10.1001/jama.2020.3072

29. Pang J, Wang MX, Ang IYH, Tan SHX, Lewis RF, Chen Jl, Gutierrez RA, Gwee SXW, Chua PEY, Yang Q etal (2020) Potential rapid diagnostics, vaccine and therapeutics for 2019 novel Coronavirus (2019ncoV): a systematic review. J Clin Med 9(3):623. https://doi.org/10.3390/jcm9030623

30. Young BE, Ong SWX, Kalimuddin S, Low JG, Tan SY, Loh J, Ng OT, Marimuthu K, Ang LW, Mak TM et al (2020) Epidemiologic features and clinical course of patients infected with SARS-coV-2 in Singapore JAMA. https://doi.org/10.1001/jama.2020.3204

31. Wang D, Hu B, Hu C, Zhu F, Liu X, Zhang J, Wang B, Xiang H, Cheng Z, Xiong Y et al (2020) Clinical Characteristics of 138 Hospitalized Patients With 2019 Novel Coronavirus - Infected Pneumonia in Wuhan, China. JAMA. https://doi.org/10.1001/ jama.2020.1585

32. Yang W, Cao Q, Qin L, Wang X, Cheng Z, Pan A Dai J, Sun Q, Zhao F, Qu J et al (2020) Clinical characteristics and imaging manifestations of the 2019 novel coronavirus disease (COVID-19):A multi-center study in Wenzhou city, Zhejiang, China. JInfect. https://doi.org/10.1016/j.jinf.2020 02.016

33. Venkataraman T, Frieman MB (2017) The role of epidermal growth factor receptor (EGFR) signaling in SARS coronavirus-induced pulmonary fibrosis. Antiviral Res 143:142-150

34. Zhang W (2020) Imaging changes of severe COVID19 pneumonia in advanced stage. Intensive Care Med. https://doi.org/10.1007/s00134-02005990-y 